\title{
Facilitating Assessments to Foster 21st Century Skills: Towards Technological Terrains
}

\author{
Sujata Wadhwa ${ }^{1}$, Dr. Audre Barlow ${ }^{2}$, Dr.Siddharthsinh Jadeja ${ }^{3}$ \\ ${ }^{1,3}$ B. H. Gardi College of Engineering \& Technology Rajkot, Gujarat, India \\ ${ }^{2}$ Shri M P Shah Arts and Science College \\ Surendranagar, Gujarat, India
}

\begin{abstract}
With the shift from industrial age to the information age, a subsequent transformation can also be witnessed, especially in engineering education, from the traditional education system to outcome based education i.e. OBE. Computers has almost eliminated human efforts to do the routine repetitive work and hence non routine problem solving skill and other 21st century skills are demanded from the graduates, specifically from engineers. The essence of OBE is 'success for all" by empowering all the students with skills and opportunities. There are already indications that there is a considerable gap between what is expected from an engineering graduate and what is offered. This gap will considerably widen unless learning outcomes, classroom practices, learning and assessment methods are coherently crafted and implemented so as to facilitate a flexible, personalized and significantly meaningful experience for the student[1] to succeed in the workplace of 21 st century. Despite technology being the lifeblood of 21 st century and the availability of smartphones with teachers and almost all the students, the problem of individual interaction and one-to-oneassessment is prevalent.
\end{abstract}

\footnotetext{
Sujata Wadhwa

B. H. Gardi College of Engineering

\& Technology Rajkot, Gujarat, India
}

This research study explores technology to enhance students' engagement in the learning process to promote the inculcation of 21 st century skills and facilitate the development of life-long learning. The authors also propose personal assessment and peer feedback, at regular intervals, followed by the mentor feedback and experts' comments

The authors also propose personal assessment and peer feedback, at regular intervals, followed by the mentor feedback and experts' comments as the best tool of inculcating and continuously assessing the $21 \mathrm{st}$ century skills essentiallyrequired among the fresh engineers.

\section{Keywords- 21st Century Skill, Assessment,OBE}

\section{Introduction:}

A. The Lacuna Identified

Engineering Education in India is undergoing a transformational phase where OBE is the focus. The essence of OBE is 'success for all" by empowering all the students with skills and opportunities.An apparent paradigm shift from knowledge to skill has resulted in emphasizing the inculcation and demonstration of the skills constantly and comprehensively as required by the 21 st century engineers. According to The Glossary of Education Reform, "the term 21st century skills refers to a broad set of knowledge, skills, work habits, and character traits that are believed-by educators, school reformers, college professors, employers, and 
others-to be critically important to succeed in today's world, particularly in collegiate programs and contemporary careers and workplaces". [2]The real picture is different with astounding facts.Many surveys prove that collaboration skills, creativity and innovation, digital literacy, communication skills and some innate qualities as integrity, honesty, accountability, etc. are prioritized much more than technical skills among engineers. The World Bank survey by Bloom and Saeki clearly highlights the skill gap amongst the engineers. These findings suggest that engineering education institutions should: (i) seek to improve the skill set of graduates; (ii) recognize the importance of Soft Skills, (iii) refocus the assessments, teaching-learning process, and curricula away from lower-order thinking skills, such as remembering and understanding, toward higher-order skills, such as analyzing and solving engineering problems, as well as creativity; and (iv) interact more with employers to understand the particular demand for skills in that region and sector. [3]According to the National Association of Software and Services Companies,(NASSCOM) , only $15-18 \%$ of the graduate engineers are employable[4]The National Employability Index of 2013 also shows only $18.33 \%$ of engineering graduates are employable and $10.03 \%$ getjobs.[5]

\section{B. Rationale for the Lacuna:}

In the conventional teaching system in engineering colleges in India, the faculty members or teachers spend most of their time in planning and delivering the content in classroom or lab and partially in checking and correcting the submitted assignments and answer sheets. The traditional curriculum of engineering education, especially in India only focus on the hard skills where students passively absorb information and then barf it during the examinations. [6] The curriculum completion and evaluation in terms of assessing, labeling and credentialing the students form the important components of the conventional system of engineering education. Assessment and evaluation, internal and external, is in the form of written assignments, mid-semesters, examinations, viva-voice and/or presentations which is purely in tune with the bookish knowledge and hardly give any chance to the student to demonstrate his learning or perform the task on the basis of the learning or knowledge acquired. There are no formal tests for assessing 21 st century skills, so the people won't know how well schools and colleges are doing in teaching these skills.[2]. Hence, to bridge this gap and to aim at 'success for all', traditional system of education is not a viable option

\section{Focusing Assessment:}

To be compatible with the information age market, the students need to be prepared for continuous learning and improvement challenges. [7]. Secondly, OBE is also geared to providing concrete, useful information to parents, employers, and colleges regarding the actual performance abilities of students[7] which is certainly and only possible with the advent and effective use of technology. As OBE focuses on individual learner and his improvement to accomplish the exit outcomes and authenticated assessment records of each learner, the authors have discussed in the paper the assessment methods which are still a challenge and an area to research in the implementation of OBE. A common problem in today's classrooms while implementing $\mathrm{OBE}$ is teacher-student interaction and individual assessments, especially at university level where the students' numbers ranges from 60 to 100 in each lecture class. Due to the time constraint the students are not given chance to think and reflect upon their learning. One to one communication, clarification, guidance and feedback for the teacher becomes impossible. Despite technology being the lifeblood of 21 st century and the availability of smartphones with teachers and almost all the students, the problem of individual interaction and assessment is prevalent. This research study presents exploring the smartphones and mobile technology to enhance students' engagement in the learning process to promote the inculcation of 21 stcentury skills and facilitate the development of life-long learning with enjoyment.The authors also propose personal assessment and peer feedback at regular intervals across the program followed by the mentor feedback and experts' comments as the best way of inculcating and continuouslyassessing 21 st century skills essential for the fresh engineers.

\section{Fostering $21^{\text {st }}$ Century Skills}

Keeping the 21 st century skills as ends in mind and with the aim of bridging this ever increasing skill gap, the 4 days activity based orientation programfor the students of 1st year was arranged w.r.t. OBE and 21st century graduate attributes in the light of Blooms Taxonomy[8]. According to the adult learning theory, adults learn when they feel there is a need for them to learn.[9]This orientation changed the perspective of 
the students'on learningprocess and elucidated what is needed form then as 21 st century engineers. It alsoserved the authors with very useful information about the family background, learning styles, language proficiency etc. of the learners which further aided to design a special framework of instructional flexible strategies with a hybrid model of an array of assessments.. Itwas discussed with the stakeholders, parents, students and faculty members to facilitate the developmentand honing of 21 stcentury skills, in particularwith an outcome of an elaborated PAC i.e. Performance Assessment Cardof each learner at the end of the year.The execution process comprised of three phases carried overacross the year with feedback at regular intervals:

\section{A. Learning:}

Real life situations and some topics of general interest brushed with the nuances of English language through peer or group discussion or role play. Every sessionended with"think and reflectupon mylearning." ,the essence of each session of 2 hours. The teacher talk time was 15 to $20 \mathrm{~min}$.

A. Performance(in various activities catering to inculcation of 21 st century skills) Nine activities as a result of personal assessment were finally selected and all the students participated and performed in at least 5 activities, one activity every week. They performed in front of the entire class and were observed by the experts supported withthepeer feedback. At the end, each student had a graph of his progress in terms of confidence, stage fear, fluency, flexibility,accountability, collaboration skillsetc.

\section{B. Assessments:}

( Comprehensive and Consistent Personal Assessment i.e. CCPA: Comprehensive and Consistent Personal Assessment: At the end of 1st semester, a Comprehensive and Consistent assessment Forma was filled by the learners that included the fields pertaining to the personal information of the student, his academic details, interests and hobbies, SWOT analysis, achievements, tours and trips and his participation in curricular and co -curricular activities along with expert's remarks The form included the self-assessment of the student on the basis of his/her learning style and the personality type. Other important component of the form included self-appraisal for LSRW skills, communication skills, flexibility, negotiation skills, digital literacy, inter personal skills, confidence etc. All these fields were to be filled by the student himself and later evaluated by the expert.

u The second section termed as Observation by the experts i.e. $\mathrm{ObE}$ was also incorporated with special attention to communication skills, thinking skills, confidence, personality and focus. This was to be filled by the experts who attended to each student individually in a face-to-face interview with the expert panel. Each learner was suggested an alternate learning pathway, an individualized retort, remediation activity to remove the gap, where ever required.

口 The third unique component of the form was the activity assessment sectioni.e. AA: The performance of each student in the series of activities like group discussion, paper reading, extempore, 1 min. my choice, debate was to be assessed by the experts, different for each of the 6 different activities. Each activity was executed in the time frame of 1 hour, where in individually or in groups, the student had to perform in front of their peers and the experts. In this way with a team of 16 experts, the whole task was accomplished to finally find out and later filling the lacuna.

( Self-Assessment(SA), Peer-assessment (PA), assessment by mentors (MA) using smart phones to enhance their engagement: The three layers of assessment was designed to increase the authenticity of the process. The students were to assess all the members of their respective groups once a month, four times in a semester or the following skills shown in the Fig. 1 below.

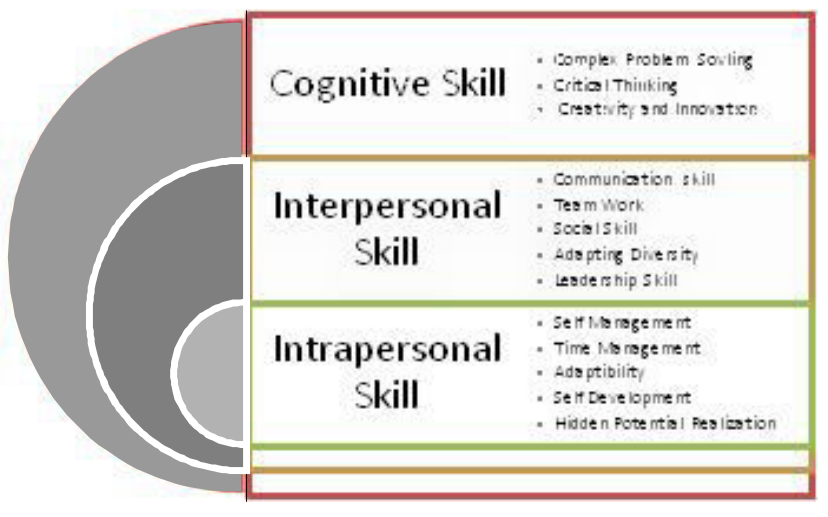

Fig. $1: 21$ st Century Skills

( The students were made aware of all the traits or skills through focus groups at the onset of the 2nd 
semester.Subsequently, during the weekly learning sessions the students were given a chance to discuss their own real life examples in day-to-day life inwhich some students had practically demonstrated some traits like honesty, flexibility, accountability and skills like collaboration, digital literacyetc. They were to assess each other at regular intervals using their smartphones. Each student and faculty owns and uses a smart phone now-a-days. Using mobile applications to encourage a student-centered approach to learning also leads to improved motivation, engagement and performance. In this sense, many studies have been conducted to improve students' performance and overcome the limitation of the traditional lecture, like improving individual and collaborative learning.[10]

૫ The online feedback form enumerated 18 skills and traits, which were to be graded on the scale of 1 to 4 where 1stands for needs improvement and 4 for excellence.

口 After filling the per-review form substantiated with the apt comments and compliments for whom the feedback is given, a motivational discussion about different fields pertaining to the skills or innate qualities in the form was held with the mentor or an expert in the presence of all the group members. Some of the asked questions were:

口 Who shows the leadership skills and how?

u What do you opine about your leader w.r.t

口 confidence?

․ Why is this person accountable?

口 How is this learner excellent in communication skills?

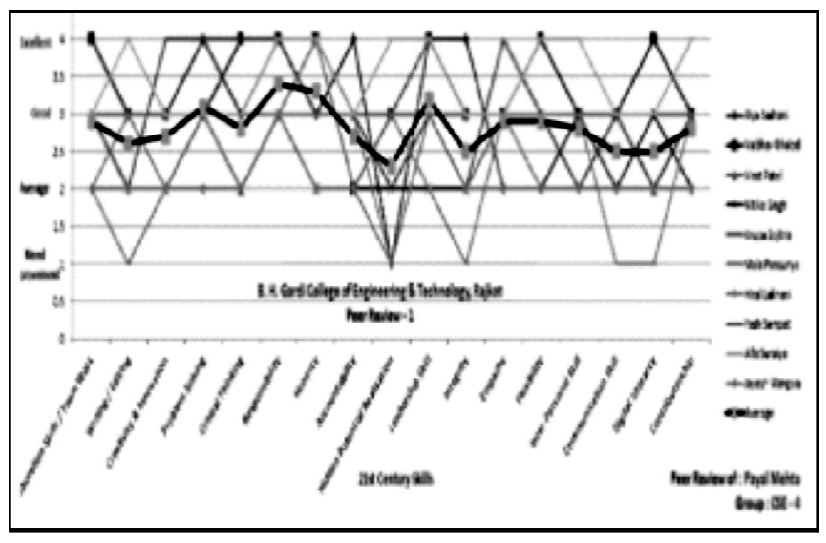

A sample of such feedback report is shown in the Fig. 2. It pertains to one of the students of one of the group who had been reviewed in all the 18 listed skills by all 10 peers of the group. The line in black color shows the average of reviews done by 10 peers. The graph gives the clear cut indication of the improvement required in terms of communication skill, digital literacy whereas the girl is good in

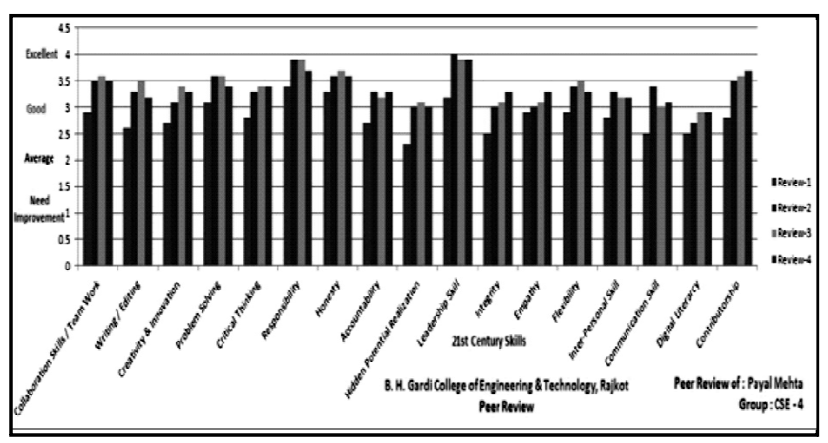

leadership skill and responsibility and honesty. Every peer has also supported his/her assessment with observation and incident comment which becomes the learning for himself as well as others.

\section{Fig. 2 Peer Review 1}

Q This peer review process was undertaken by all the students in one semester, and improvements are evidentin the Fig 3 below. The purple bar showing the result of the fourth review supports the improvements and also highlights the opportunities seeking improvement.

\section{Fig. 3 Peer Review (Final)}

\section{Discussions And Implications:}

This type of brain storming sessions and heated up discussions, at times, provided an elaborative exposure to the demonstration of varied skills and their importance in our lives to get success. A new learning experience exhibiting the right skills was conceptualized and the students came to know about the real meaning and the demonstration of each skill and traits, gradually moving towards perfection in acquiring and exhibiting them. Some discussions also proved to be eye-openersfor some learners who at their first attempt filled the inaccurate or biased feedback for their close friends. But later with the realization that it could have adverse effects on him as well as on his friends, these improper feed-backs became constructive ones. while attempting these assessment strategiesto ascertain and authenticate the acquisition of 21 st century skills or to validate 
demonstrations of learning, or project-based learning which tend to be cross-disciplinary in nature, and students-in the process of completing an assigned project, in this case, technical script writing, peerreview form etc., may have to use a variety of applied skills, multiple technologies, and new ways of looking at human behavior while also taking initiative, thinking creatively, planning out the process, and working collaboratively in teams with other students.[2] The rewarding repercussions are evident in hopeful, self-motivated and self-regulated students who are energetic and look at challenges as opportunities. Generally high-hope people experience less anxiety and less stress specific to test-taking situations. [11]The conducive environment essential for any type of learning coupled with enhancing the engagement of learners for their better performances of the acquired skills is another upshot. The "Culture of Collaboration and Contributor ship" is witnessed amongst all the first year entrants who very enthusiastically exhibit the persistent spirit to help and are ever ready to contribute. The trust and long lasting relationship has sprouted from the permanent bonding exhibited during the assessment process and during the conduction of the activities making the three layered assessment method more consistent, reliable and effective. The use of smartphones for the assessment process, recordings, clicking pictures, online searching, giving feedbacks allowed the students to work from anywhere and at their comfort. A thorough grounding in 21 st century skills encouraging the student to be independent where students take responsibility for their own learning has been initiated. Peer-feed back when given by the students, itself serves as a self- assessment or selfappraisal. The process becomes a tool to facilitate the skills or traits. Another remarkable reverberation is that thinking and reflecting on their ways of dealing, doing and learning enabled them to invigorate their thinking and learning process.

\section{Challenges:}

1. Some students do not have access to internet $24 * 7$. It resulted in unexpected delay in the feed-back. However, they were assisted by their friends or batch mates.

2. Some students were not technology savvy but this obstacle was overcome with the help of their group members, providing them the opportunity to play the role of teachers to explain the process.
3. All the students may not fill the feed-back forms with utmost sincerity and involvement.

4. Some students found it to be tedious and time consuming.

5. Some students do not consider the feed-back from their peers to be worthy and require the endorsement from the mentors or the experts.

\section{Concluding Remarks:}

The paper is exploratory in nature offering an array of assessment strategies to foster 21 st century skills. It provides an opportunity to develop the culture of collaboration and contributorship. It allows assessment for learning (as opposed to the traditional assessment of learning), ultimately facilitating engagement of the students in the learning process. Well-orchestrated and multitudes of assessment methods targeting the fostering of $21 \mathrm{t}$ century skills among the engineering graduates is one of the prime requisites in the implementation of OBE in India. This also is in tune with the learning styles of modern digital natives.[12]With this strategy, the teachers and the learners are certainly benefitted by adopting and adapting to the technology which is mushrooming at a lightning pace.It uses technology to promote learning and making the teaching-learning process studentcentered, not content-centered or teacher-centered. An individualized approach and giving feed-back at the onset of the engineering program facilitate the realization of the skill gap and acquisition of the essential skills. The assessment process also serves as a tool to improve with internalization. The authors also believe that the innate qualities like honesty, integrity, empathy etc. can't be measured. This paper further makes a case for how we need to explore the methods and modules of assessments to advance our understanding of 21 st century skillsthat makes it pertinent to students' success.

\section{Acknowledgments:}

The authors are so much thankful to Prof Kapil Shukla for his support and expertise to guide the students and manage this mammoth data base.

\section{References}

[1] K. R. Laxminarayanan Samavedham, "'Facilitating 21st Century skills in Engineering Students" ," The Journal of Engineering 
Education, , vol. Vol. XXVI, no. 1,pp. 1-11.

[2] "21st Century Skills," 4 October 2014. [Online]. Available: http://edglossary.org/21st-centuryskills/.

[3] H. S. Andreas Blom, "Employability and Skill set of Newly graduated Enginners in India," The World bank Policy Research paper, pp. 15-18, April 2011.

[4] M. M. Dhananjay G. Thombare, "Personality mapping of entry level Engineering students for assessment of Engineering Competencies," in 2 nd International Conference on transformations in Engineering Education, Banglore, 2015.

[5] "National Employability Report," 2014. [Online]. Available: www.aspiringminds.in.

[6] K. K. Richa Mishra, "Defining Learning $\mathrm{Outcomes}$ of $\mathrm{Co}-\mathrm{curricular}$ Activities:Integrating Desired commanlaties," in 2nd International Confrence on Transformations in Engineering Education, Banglore, 2015.

[7] W. G. Spady, "Outcome Based Education : Critical Issues and Answers," American Association of School Administartors, 1994.
[8] B. B. S., Taxonomy of Educational Objectives Hndbook I : The Cognitive Domain,, New York: David McKay Co Inc, 1956.

[9] S. D. Brookfield, "Understanding and Facilitating Adult Learning," School Library Media,pp. 99-105, 1988.

[10] E. A. W. Athraa al Mosawi, "Exploring the Potential of Mobile Applications to support Learning and Engagement in Elementary Classes," International Journal of Mobile and Blended Learning, pp. 33-44, April-June 2015.

[11] T. O. Ross Markle, "Assessing Affective Fcators to improve Retention and Completion," November 2014. [Online]. Available: https://www.ets.org/s/successnavigator/pdf/lear ning_abstracts_markle_obanion.pdf. [Accessed February 2015].

[12] M. Prensky, "Digital Natives, Digital Immigrants," October 2001. [Online]. Available: http://www.marcprensky.com. [Accessed 2015]. 